\title{
Colorectal cancer screening using flexible sigmoidoscopy: United Kingdom study demonstrates significant incidence and mortality benefit
}

\author{
Robert J Hilsden MD PhD FRCPC, Alaa Rostom MD MSc(Epid) FRCPC
}

Relying on flexible sigmoidoscopy is as clinically logical as performing mammography of one breast to screen women for breast cancer.

$\mathrm{T}$ his widely held sentiment, expressed in an influential editorial published in the New England Journal of Medicine in 2000 (1), helps explain the dramatic drop in rates of flexible sigmoidoscopy in Canada and the United States, at the same time that colonoscopy rates have increased (2-4). Despite strong evidence from observational studies that sigmoidoscopy reduces the incidence and mortality of colorectal cancer (CRC) (5), and its inclusion as a recommended test in several clinical practice guidelines (6-8), no serious consideration has been given to the use of flexible sigmoidoscopy as a screening tool in Canada and most other jurisdictions. The recent publication of results of the United Kingdom (UK) Flexible Sigmoidoscopy Screening Trial should lead care providers, program planners and funders to re-evaluate the role of flexible sigmoidoscopy in CRC screening (9).

The UK trial investigators randomly assigned 170,432 individuals 55 to 64 years of age to either once-only flexible sigmoidoscopy or no screening in a 1:2 ratio. Recruitment and screening occurred between November 1994 and March 1999. The sample size was calculated to give $90 \%$ power to detect a $20 \%$ difference between groups in the incidence of CRC at 10 years and mortality at 15 years from randomization. Flexible sigmoidoscopies were performed in hospital endoscopy clinics. Small polyps were removed at sigmoidoscopy. Colonoscopy was recommended for those with polyps that met high-risk criteria: $1 \mathrm{~cm}$ or larger; three or more adenomas; tubulovillous or villous histology; severe dysplasia or malignancy; or 20 or more hyperplastic polyps above the distal rectum. New cancer diagnoses were identified from cancer registries, hospital databases and the National Health Service Bowel Cancer Screening Programme databases. Participants were followed for a median of 11.2 years.

In the intention-to-treat analysis, CRC incidence in the intervention group was reduced by $23 \%$ (HR 0.77; 95\% CI 0.70 to 0.84 ) and mortality by $31 \%$ (HR $0.69 ; 95 \%$ CI 0.59 to 0.82 ). In a per-protocol analysis that included the $71 \%$ of patients randomly assigned to flexible sigmoidoscopy who completed screening, the incidence of CRC was reduced by $33 \%$ and mortality by $43 \%$. This compares favourably with the $25 \%$ mortality reduction in those who completed at least one round of fecal occult blood test (FOBT) screening (10). The incidence of cancer of the rectum and sigmoid colon was reduced by $50 \%$.
The numbers needed to be screened to prevent one CRC diagnosis or death were 191 (95\% CI 145 to 277) and 489 (95\% CI 343 to 852 ), respectively.

The magnitude of the incidence and mortality reduction seen in the UK study is remarkable for several reasons. First, individuals underwent only a single flexible sigmoidoscopy, yet the risk of incident cancers of the rectum and sigmoid colon was reduced by at least 10 years. Second, the criteria for proceeding to colonoscopy were quite strict. Only 5.3\% of individuals were referred for colonoscopy. Another 20\% with 'low-risk polyps' were discharged with no further follow-up. Third, although the $60 \mathrm{~cm}$ flexible sigmoidoscope can be advanced to the splenic flexure, endoscopists in the UK trial were "advised to advance the scope as far as possible without causing undue pain or distress (normally to the sigmoid colon/descending colon junction)" (11).

Three other randomized controlled trials $(12-14)$ that are currently underway will provide additional evidence on the effectiveness of screening by flexible sigmoidoscopy. One of the trials, the Norwegian Colorectal Cancer Prevention (NORCCAP) study (13), reported results on the risk of CRC following a seven-year follow-up period. In contrast to the UK study, the NORCCAP study investigators randomly assigned individuals using a population registry before inviting them to participate in the study. Of those randomly assigned to flexible sigmoidoscopy, $67 \%$ attended for screening. In the intention-to-treat analysis, no difference was found in the seven-year cumulative incidence of CRC between the flexible sigmoidoscopy and control groups (134.5 versus 131.9 cases per 100,000 person years, respectively). However, when only those who attended screening were included in the analysis, a substantial reduction in mortality for both total CRC (HR 0.41) and rectosigmoid cancer (HR 0.24) was found. This secondary analysis more closely mimics what was performed in the UK study and, thus, provides validation of the UK results. Because the four trials vary in terms of eligibility criteria, screening frequency, criteria for colonoscopy and instrument used $(60 \mathrm{~cm}$ or $140 \mathrm{~cm}$ endoscope), they will provide a wealth of information to understand the most effective way to deliver flexible sigmoidoscopy screening.

In 2010, we now have randomized controlled trial-level evidence supporting the use of FOBT and flexible sigmoidoscopy for screening individuals at average risk for CRC. Where does that leave colonoscopy - arguably the most popular and

Departments of Medicine and Community Health Sciences, University of Calgary; and Forzani Eु MacPhail Colon Cancer Screening Centre,

Alberta Health Services, Calgary, Alberta

Correspondence: Dr Robert J Hilsden, University of Calgary, 3330 Hospital Drive Northwest, Calgary, Alberta T2N 4N1.

Telephone 403-210-9355, fax 403-283-6151, e-mail rhilsden@ucalgary.ca

Received for publication June 15, 2010. Accepted June 18, 2010. 
preferred screening test? It is becoming increasingly difficult to argue that if flexible sigmoidoscopy is good, colonoscopy should be even better. There is an imperative need for better evidence supporting primary screening colonoscopy that demonstrates that it is not just expensive and risky flexible sigmoidoscopy. The best evidence supporting primary colonoscopy screening comes from methodologically weak cohort studies using nonconcurrent controls $(15,16)$. The analogy of flexible sigmoidoscopy to screening a single breast by mammography - although intuitively appealing - has not held up because there is clearly something different between endoscopic screening of the right and left colon (17-19). The underlying basis for this difference remains to be defined - biological differences, technical limitations of current colonoscopies or inadequate performance. In the meantime, it is incumbent on endoscopists who provide screening colonoscopy to those at average risk for CRC to exercise meticulous care to detect and remove all polyps, and to audit their own performance, paying particular attention to their withdrawal times and adenoma detection rates, to ensure that they are providing high-quality colonoscopy. It should be noted that important variability in the rates of positive screens, and in polyp and adenoma detection rates have also be reported among flexible sigmoidoscopy examiners (20).

In 2010, several provinces in Canada have either embarked on or are developing population-based CRC screening tests based on either a guaiac or immunochemical FOBT. Should

\section{REFERENCES}

1. Podolsky DK. Going the distance - the case for true colorectal cancer screening. N Engl J Med 2000;343:207-8.

2. Hilsden RJ. Patterns of use of flexible sigmoidoscopy, colonoscopy and gastroscopy: A population-based study in a Canadian province. Can J Gastroenterol 2004;18:213-9.

3. Schultz SE, Vinden C, Rabeneck L. Colonoscopy and flexible sigmoidoscopy practice patterns in Ontario: A population-based study. Can J Gastroenterol 2007;7:431-4.

4. Meissner HI, Breen N, Klabunde CN, Vernon SW. Patterns of colorectal cancer screening uptake among men and women in the United States. Cancer Epidemiol Biomarkers Prev 2006;15:389-94.

5. Selby JV, Friedman GD, Quesenberry CP Jr, Weiss NS. A case-control study of screening sigmoidoscopy and mortality from colorectal cancer. N Engl J Med 1992;326:653-7.

6. Canadian Task Force on Preventive Health Care: Colorectal cancer screening. Recommendation statement from the Canadian Task Force on Preventive Health Care. CMAJ 2001;165:206-8.

7. Winawer S, Fletcher R, Rex D, et al. Colorectal cancer screening and surveillance: Clinical guidelines and rationale - update based on new evidence. Gastroenterology 2003;124:544-60.

8. Leddin D, Hunt R, Champion M, et al. Canadian Association of Gastroenterology and the Canadian Digestive Health Foundation: Guidelines on colon cancer screening. Can J Gastroenterol 2004;18:93-9.

9. Atkin WS, Edwards R, Kralj-Hans I, et al; UK Flexible Sigmoidoscopy Trial Investigators. Once-only flexible sigmoidoscopy screening in prevention of colorectal cancer: A multicentre randomised controlled trial. Lancet 2010;375:1624-33.

10. Hewitson P, Glasziou P, Watson E, Towler B, Irwig L. Cochrane systematic review of colorectal cancer screening using the fecal occult blood test (hemoccult): An update. Am J Gastroenterol 2008;103:1541-9.

11. Atkin W, Rogers P, Cardwell C, et al. Wide variation in adenoma detection rates at screening flexible sigmoidoscopy. Gastroenterology 2004;126:1247-56. these programs incorporate primary screening by flexible sigmoidoscopy? Clearly, there would be substantial challenges to implementing population-based flexible sigmoidoscopy screening in Canada. Currently, it is unlikely that there are adequate endoscopy resources, either in terms of facilities or personnel. However, fewer resources would be required than for primary colonoscopy screening. In the UK trial, a median of 12 people were screened in each $3 \mathrm{~h}$ session, which is likely at least double what could be accomplished with high-quality colonoscopy. The use of nonphysician providers could reduce the impact on existing endoscopist resources. Flexible sigmoidoscopy may also be less appealing to the general public and result in lower screening uptake rates than stool-based tests. In a randomized trial of different screening tests conducted in the Netherlands (21), the participation rate was $61.5 \%$ for a fecal immunochemical test and 32\% for flexible sigmoidoscopy. However, flexible sigmoidoscopy screening detected a substantially greater number of individuals with advanced neoplasia, which suggests that it may result in a greater reduction in CRC incidence and mortality in the population despite a lower uptake.

In summary, the UK Flexible Sigmoidoscopy Screening Trial provided high-level evidence that flexible sigmoidoscopy results in a substantial reduction in CRC mortality and incidence. The role of flexible sigmoidoscopy in opportunistic and population-based screening needs to be re-evaluated.

12. Segnan N, Senore C, Andreoni B, et al; SCORE Working Group: Baseline findings of the Italian multicenter randomized controlled trial of "once-only sigmoidoscopy" - SCORE. J Natl Cancer Inst 2002;94:1763-72.

13. Hoff G, Grotmol T, Skovlund E, Bretthauer M; Norwegian Colorectal Cancer Prevention Study Group. Risk of colorectal cancer seven years after flexible sigmoidoscopy screening: Randomised controlled trial. BMJ 2009;338:b1846.

14. Weissfeld JL, Schoen RE, Pinsky PF, et al; PLCO Project Team. Flexible sigmoidoscopy in the PLCO cancer screening trial: Results from the baseline screening examination of a randomized trial. J Natl Cancer Inst 2005;97:989-97.

15. Kahi CJ, Imperiale TF, Juliar BE, Rex DK. Effect of screening colonoscopy on colorectal cancer incidence and mortality. Clin Gastroenterol Hepatol 2009;7:770.

16. Winawer SJ, Zauber AG, Ho MN, et al. Prevention of colorectal cancer by colonoscopic polypectomy. The National Polyp Study Workgroup. N Engl J Med 1993;329:1977-81.

17. Singh G, Gerson LB, Wang H, et al. Screening colonoscopy, colorectal cancer and gender: An unfair deal for the fair sex? Digestion 2007;64. (Abst)

18. Baxter NN, Goldwasser MA, Paszat LF, Saskin R, Urbach DR, Rabeneck L. Association of colonoscopy and death from colorectal cancer. Ann Intern Med 2009;150:1-8.

19. Baxter NN, Rabeneck L. Is the effectiveness of colonoscopy "good enough" for population-based screening? J Natl Cancer Inst 2010;102:70-1.

20. Pinsky PF, Schoen RE, Weissfeld JL, Kramer B, Hayes RB, Yokochi L; PLCO Project Team. Variability in flexible sigmoidoscopy performance among examiners in a screening trial. Clin Gastroenterol Hepatol 2005;3:792-7.

21. Hol L, van Leerdam ME, van Ballegooijen M, et al. Screening for colorectal cancer: Randomised trial comparing guaiac-based and immunochemical faecal occult blood testing and flexible sigmoidoscopy. Gut 2009;59:62-8. 


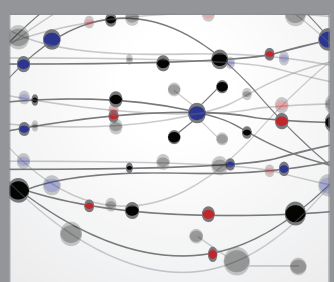

The Scientific World Journal
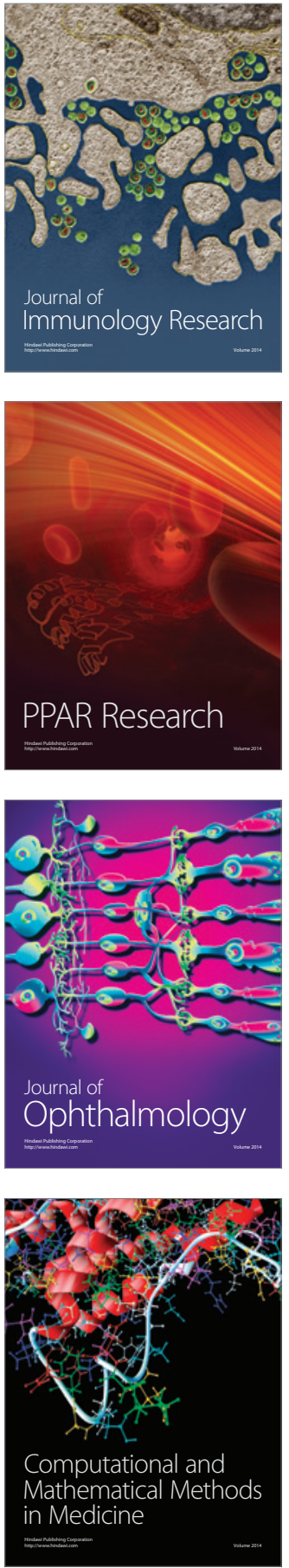

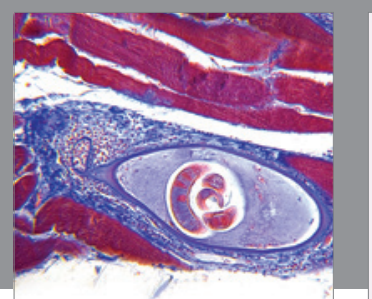

Gastroenterology Research and Practice

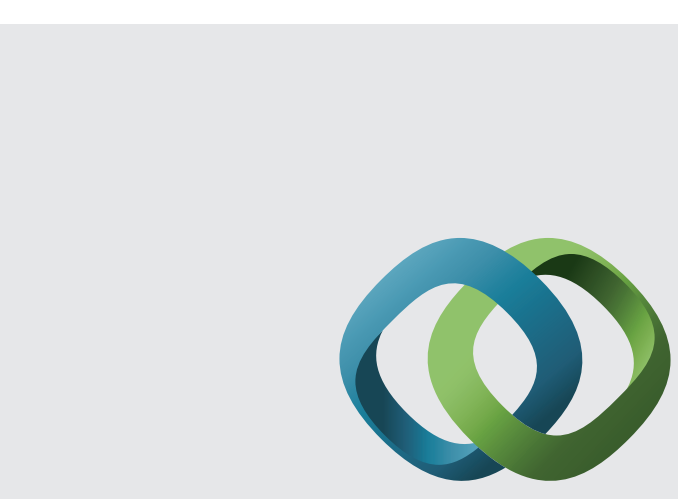

\section{Hindawi}

Submit your manuscripts at

http://www.hindawi.com
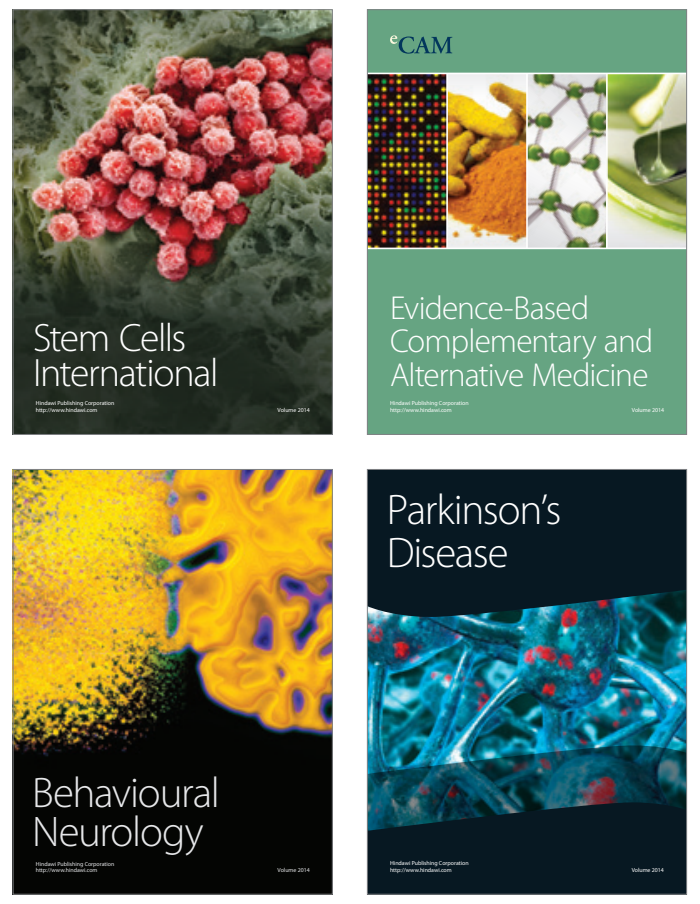
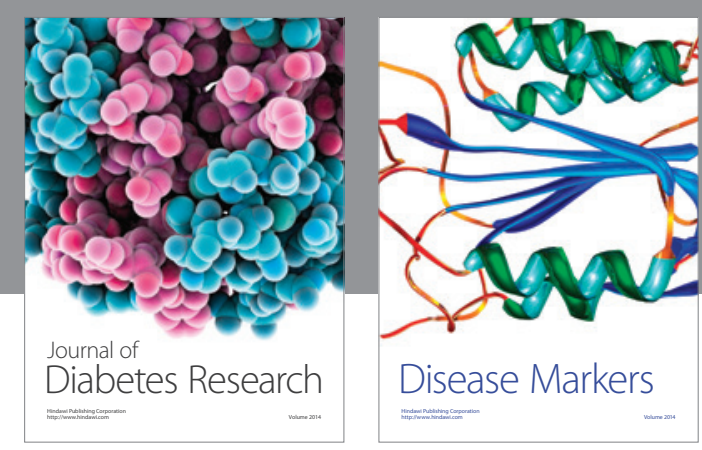

Disease Markers
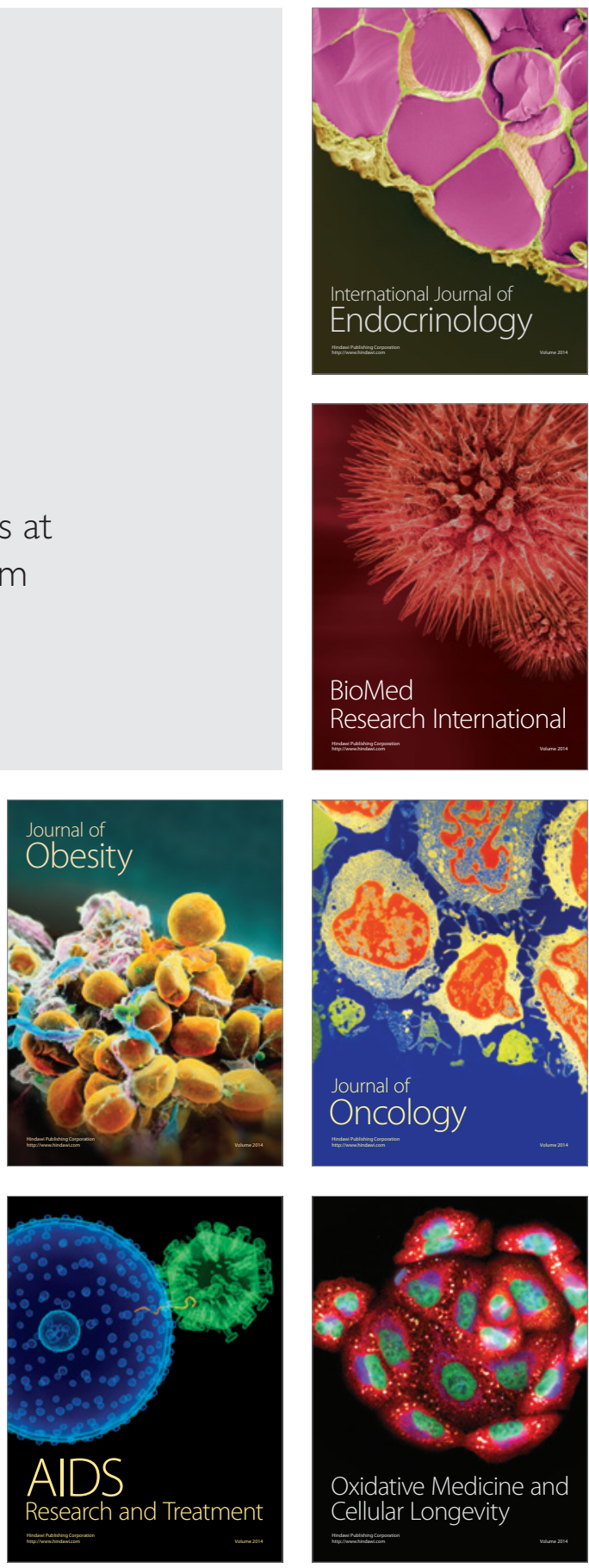